Т.В. Колесник, А.В. Надюк, А.А. Косова, М.Г. Киричко, В.В. Белецкий

Государственное учреждение «Днепропетровская медицинская академия Министерства здравоохранения Украины»

Н.М. Гейтур , Л.А. Кудрявцева, В.Л. Резникова ${ }^{3}$, Т.Ф. Терешина $a^{4}$, А.А. Мирошниченко

Л.В. Польша', О.П. Украинец, Л.О. Лисовская ${ }^{10}$, Н.Н. Пинчук'

В.И. Денисова ${ }^{15}$, А.М. Борденюк ${ }^{15}$

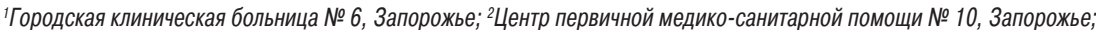
${ }_{3}^{3}$ Поликлиника Министерства внутренних дел, Запорожье; ${ }^{4}$ Поликлиника городской больницы № 15, Днепр; ${ }^{5}$ Областная клиническая больница имени Мечникова, Днепр;

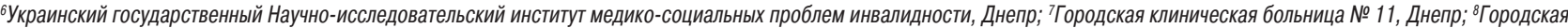

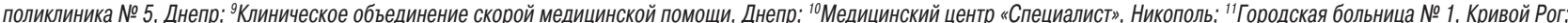

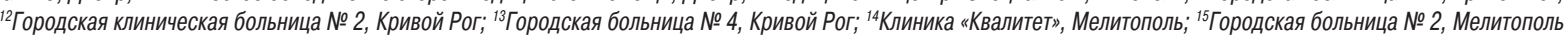

\title{
Тревожно-депрессивные расстройства у пациентов с сердечно-сосудистыми заболеваниями в клинической практике: возможности терапии
}

В статье изучена частота клинически выраженных форм и субклинических проявлений тревоги и депрессии у 153 пациентов с сердечно-сосудистыми заболеваниями, оценена эффективность терапии тревоги и депрессии у этих больных препаратом Медопрам в течение 6 мес. Подтверждена значительная распространенность тревожно-депрессивных расстройств у пациентов с кардиоваскулярной патологией, что свидетельствует о необходимости включения стандартизированных диагностических методов в комплексное клинико-инструментальное обследование больных для своевременного выявления клинически значимых тревоги и депрессии. Высокая эффективность, безопасность, хорошая переносимость и низкий потенциал межмедикаментозного взаимодействия подтверждают особенное значение эсциталопрама (Медопрам) в лечении тревожнодепрессивных расстройств у больных различного возраста с сердечно-сосудистыми заболеваниями и дают основания рассматривать его в качестве средства выбора в терапии этих пациентов в клинической практике.

Ключевые слова: тревога, депрессия, сердечно-сосудистые заболевания, эсциталопрам, Медопрам.

\section{Актуальность проблемы}

В современном мире психическое нездоровье-вторая по значимости причина потери трудоспособности после сердечнососудистых заболеваний (ССЗ). Согласно данным Всемирной организации здравоохранения, депрессия - одно из самых распространенных психических расстройств и основная причина инвалидности в мире, вносящая значительный вклад в глобальное бремя всех болезней. По оценкам от депрессии страдают >300 млн человек всех возрастных групп (World Health Organization, 2017). Наиболее часто депрессивные расстройства отмечают в возрасте 30-40 лет, у женщин - в 2 раза чаще, чем у мужчин. До 15\% пациентов с депрессией совершают суицидальные попытки (Мосолов С.Н., Калинин В.В., 1998; Kaplan H.I., Sadock B.J., 1998).

В общей популяции депрессивные расстройства отмечают в 5-17\% случаев. В условиях специализированных психиатрических учреждений амбулаторного звена они составляют примерно 1\%. При массовом обследовании на промышленных предприятиях те или иные депрессивные нарушения выявляют у $26 \%$, а среди обратившихся к специалистам общей практики - у $68 \%$ людей (Мосолов С.Н., Калинин В.В., 1998; Марута Н.А., Мороз В.В., 2002; Михайлов Б.В., 2003; Самушия М.А., Вечеринина К.О., 2005). До 80\% лиц с данной патологией впервые обращаются за медицинской помощью к терапевтам, при этом депрессию распознают у каждого 4-го и лишь в 50\% случаев назначают адекватную терапию (Долженко М.Н., 2013). Проблему лечения депрессии усугубляет очень незначительная доля первичных обращений по поводу данного заболевания $-4,7 \%$ (Пинчук И.Я., 2010).

\section{Взаимосвязь депрессии и СС3}

Проблема сочетания депрессии и ССЗ представляется особенно значимой не только ввиду широкой распространенности этих расстройств, но и в связи с возрастанием смертности от ССЗ в последние годы (Чазов Е.И., 2003). По оценкам распространенность депрессивных состояний у больных ССЗ варьирует в пределах 18-65\% (Musselman D.L. et al., 1998; Januzzi J.L.Jr. et al., 2000).

Во многолетнем контролируемом исследовании J.C. Barefoot и соавторов (1996) установлено, что у лиц с депрессией риск заболеть ишемической болезнью сердца (ИБС) и перенести инфаркт миокарда (ИМ) почти в 2 раза выше, чем у лиц без депрессии. По данным F. Lesperance и соавторов (1996), у 27,5\% больных, перенесших ИМ, отмечен по меньшей мере один эпизод выраженной депрессии в течение жизни. До ИМ 7,7\% перенесли депрессивный эпизод в течение года, предшествовавшего ИМ, у $31,5 \%$ выявлена депрессия во время пребывания в стационаре или в течение года после выписки. При этом появляется все больше данных о существенном повышении риска смертельных исходов после перенесенного ИМ и других критических состояний кардиоваскулярной природы при их сочетании с депрессией.

По результатам EUROASPIRE III, среди 8580 пациентов из 22 европейских стран, которых наблюдали в течение 6 мес после госпитализации по поводу ИБС, распространенность депрессии варьировала в пределах 8,2-35,7 и 10,3-62,5\%, тревожных расстройств - 12,0-41,8 и 21,5-63,7\% среди мужчин и женщин соответственно (Pająk A. et al., 2013).

Показано, что депрессия - механизм, частично определяющий качество жизни больных артериальной гипертензией (АГ) (Tsartsalis D. et al., 2016).

Возросший интерес к проблеме взаимосвязи депрессивных, тревожных расстройств и ССЗ обусловлен как их широкой распространенностью, так и результатами многочисленных клинических, нейрохимических, нейрофизиологических исследований, свидетельствующих об общности некоторых патогенетических механизмов (Горина Л.В., 2011). В последние десятилетия эта взаимосвязь стала предметом масштабных исследований, включая клинико-эпидемиологические исследования с оценкой эф- 
фективности и безопасности новых антидепрессантов, не оказывающих кардиотоксического действия (Васюк Ю.А. и соавт. , 2012).

\section{Терапия депрессивных расстройств}

В настоящее время клиницистам предоставлены большие возможности выбора методов терапии депрессивных расстройств: психофармакотерапия антидепрессантами с разными механизмами действия и различные формы психотерапии (Горина Л.В., 2011). У пациентов с сопутствующими ССЗ выбор препаратов должен осуществляться с особой тщательностью, с учетом побочных действий и возможных нежелательных реакций. Приоритет сегодня отдают антидепрессантам нового поколения - селективным ингибиторам обратного захвата серотонина (СИОЗС). Количество препаратов этой группы в последние годы существенно увеличилось, что определяет сложность выбора наиболее оптимального препарата в каждом конкретном случае.

\section{Эсциталопрам}

Один из ярких представителей группы СИОЗС - эсциталопрам, активный S-энантиомер циталопрама, по праву считающийся наиболее селективным из всех доступных антидепрессантов СИОЗС. Фармакокинетика эсциталопрама линейная и дозозависимая - в диапазоне доз 10-30 мг/сут. К основным клиническим характеристикам эсциталопрама можно по-праву отнести высокую эффективность и безопасность (Хаустова О.О., 2018).

Несомненное преимущество эсцитолапрама среди других представителей СИОЗС - максимально быстрое развитие клинически значимого антидепрессивного эффекта уже к концу 1-й - началу 2-й недели лечения. При этом достигнутый эффект продолжает нарастать в течение всего курса активной терапии (8 нед), а максимальный противотревожный терапевтический эффект достигается примерно через 3 мес после начала терапии (Бурчинский С.Г., 2018).

Эсциталопрам оказывает комплексное сбалансированное действие на все основные компоненты клинической картины депрессии, демонстрируя собственно тимоаналептический, анксиолитический и активирующий эффект (Бурчинский С.Г., 2018). Это позволяет говорить о нем как об антидепрессанте сбалансированного типа действия, что свойственно далеко не всем препаратам СИОЗС.

Важными условиями эффективной и качественной лекарственной терапии являются отчетливое клиническое улучшение, хорошая переносимость лекарственного препарата и отсутствие серьезных нежелательных реакций, что зависит не только от дозы препарата, но и от лекарственных взаимодействий, индивидуальных особенностей, влияющих на метаболизм лекарственных средств. В этом контексте безопасность эсциталопрама заслуживает отдельного рассмотрения, поскольку именно указанный критерий сегодня ставится во главу угла при выборе того или иного антидепрессанта. Оценке высокой безопасности способствуют как данные о фармакокинетике эсциталопрама, так и результаты клинических исследований. К благоприятным фармакокинетическим особенностям эсциталопрама относят, с одной стороны, линейный дозозависимый характер и высокую биодоступность, с другой - образование метаболитов, обладающих крайне низкой фармакологической активностью, минимальные изменения биотрансформации с возрастом и низкий потенциал межлекарственного взаимодействия.

Перечисленные свойства свидетельствуют о высокой прогнозируемости лечения эсциталопрамом, возможности его безопасного применения в пожилом и старческом возрасте, а также в условиях полипрагмазии, что представляется весьма важными клиническими преимуществами данного препарата у больных ССЗ. Кроме того, наличие прямой корреляции между селективностью влияния на обратный захват серотонина и уровнем безопасности препаратов СИОЗС позволяет говорить об эсциталопраме как одном из наиболее безопасных представителей этого класса (Бурчинский С.Г., 2018).

Побочные эффекты при применении эсциталопрама возникают достаточно редко, характеризуются слабой выраженностью и преимущественно проходят после 2 недтерапии. Среди побочных эффектов чаще отмечают тошноту, диарею, инсомнию и нарушение эякуляции, причем первые три - исключительно на начальном этапе лечения. Терапия эсциталопрамом не оказывает существенного влияния на артериальное давление (АД) и показатели электрокардиограммы (ЭКГ) (за исключением известного свойства СИОЗС замедлять сердечный ритм). Важно подчеркнуть, что длительность приема эсциталопрама не влияет на риск развития побочных эффектов. Это позволяет безопасно применять его курсами 6-12 мес и более, что необходимо для полноценного обеспечения противорецидивного действия в отношении проявлений депрессии.

Один из наиболеедоступныхпрепаратов эсциталопрама, представленных сегодня на фармацевтическом рынке Украины и полностью соответствующий стандартам Европейского Союза, зарегистрирован под торговым названием Медопрам («Medochemie Ltd»).

Следует отметить, что за рубежом, а в последние годы и в Украине, депрессивные расстройства легкой и средней степени тяжести у больных кардиологического профиля успешно лечат кардиологи и врачи общей практики.

Цель исследования - выявить частоту клинически выраженных форм и субклинических проявлений тревоги и депрессии у пациентов с ССЗ, оценить эффективность терапии тревоги и депрессии у этих больных препаратом Медопрам в течение 6-месячного периода наблюдения.

\section{Объект и методы исследования}

В исследовании участвовали 23 врача (кардиологи, терапевты, семейные врачи) в 16 медицинских центрах Украины.

Дизайн исследования состоял из четырех этапов, на каждом из которых проводили анкетирование пациентов с ССЗ по специально разработанному протоколу.

На I визите (скрининг) проводили тщательный сбор анамнеза жизни, включающий информацию об уровне образования, трудовой занятости, семейном положении, отягощенной наследственности, активности образа жизни, статусе курения, анамнез ССЗ и оценки объективного статуса пациента. I и последующие визиты (при выявлении тревоги и/или депрессии) включали обязательное проведение оценки психологического статуса по уровню стресса (опросник L.G. Reeder и соавторов, 1968) и Госпитальной шкале тревоги и депрессии (Hospital Anxiety and Depression Scale - HADS) (Zigmond A.S., Snaith R.P., 1983), согласно которым подтверждали наличие/отсутствие тревоги и депрессии. При результате по Шкале HADS $\geqslant 8$ баллов диагностировали субклинически выраженную тревогу и/или депрессию, $\geqslant 11$ баллов клинически выраженную тревогу и/или депрессию, что служило основанием для назначения, помимо базисной терапии основного СС3, препарата Медопрам в дозе 10 мг 1 раз в сутки.

На II (через 4 нед) и III визите (через 12 нед) проводили оценку психологического и клинического статуса больных (измерение уровня АД, ЭКГ - оценка интервала $Q-T)$ с выявленной тревогой и/или депрессией с коррекцией дозы препарата Медопрам при необходимости. На IV визите (через 6 мес) выполняли окончательную оценку эффективности и безопасности препарата.

Статистическую обработку данных проводили с использованием методов биостатистики с помощью пакета программ «Statistica v.6.1 ${ }^{\oplus}$ » («Statsoft Inc.», США). Проверку соответствия распределения количественных данных нормальному закону проводили по критериям Колмогорова - Смирнова с поправкой Лилиефорса. При нормальном законе распределения статистические характеристики представлены в виде средней арифметической (М), ее стандартной ошибки ( $\pm \mathrm{m})$ и 95\% доверительного интервала (ДИ), в остальных случаях - в виде медианы (Ме) и интерквартильного размаха (25-75\%). Сравнение статистических характеристик в динамике наблюдения проводили с использованием параметрических и непараметрических критериев: проверку равенства дисперсий - по критериям Фишера (F) и Левена, оценку достоверности различий средних - по критериям Стьюдента (t) и Манна - Уитни (U). За критическое значение уровня значимости (p) принимали $\leqslant 0,05$, тенденцию отмечали при $p<0,10$.

\section{Результаты и их обсуждение}

После скрининга в исследование были включены 153 пациента с симптомами тревоги и/или депрессии: 57 (37,25\%) мужчин и $96(62,75 \%)$ женщин, средний возраст - 57 (47-65) лет. Из них $79(51,64 \%)$ человек имели высшее, 40 (26,14\%) - среднее специальное и $34(22,22 \%)$ - среднее образование. По степени занятости среди участников: 67 (43,80\%) работающих, 46 (30,06\%) пенсионеров, 40 (26,14\%) лиц трудоспособного возраста без трудовой занятости. 12 (7,84\%) человек никогда не состояли, 93 (60,78\%)состояли в браке, 21 (13,72\%) - разведены, $27(17,64 \%)$ - вдовцы. 
Образ жизни считали малоподвижным при наличии минимум 2 из 3 критериев: нахождение в положении сидя в течение дня $\geqslant 5$ ч, ходьба в течение дня <30 мин и/или занятия физкультурой $<2$ ч в неделю. Согласно этим критериям, 98 (64,05\%) пациентов имели малоподвижный образ жизни.

На момент включения в исследование 27 (17,65\%) пациентов курили, $17(11,11 \%)$ курили ранее и бросили, 109 (71,24\%) никогда не курили.

Отягощенная наследственность по хотя бы одному ССЗ выявлена у $97(63,40 \%)$ пациентов. Наличие стенокардии в анамнезе у родственников 1-й и 2-й линии родства установлено у 24 (15,69\%), постинфарктного кардиосклероза - у 15 (9,80\%), АГ - у 76 (49,67\%), острого нарушения мозгового кровообращения - у $18(11,76 \%)$, сахарного диабета 2-го типа - у $21(13,72 \%)$, ожирения - у 12 (7,84\%) человек.

Среди участников исследования АГ диагностирована у 97 (63,40\%), ИБС - у 16 (10,46\%), коморбидность ИБС и АГ у 40 (26,14\%). Медиана длительности АГ составила 7 (4-12) лет. В приеме антигипертензивных препаратов нуждались 137 человек, однако постоянно применяли их на момент включения в исследование лишь 55 (40,14\%), эпизодически - 54 (39,42\%), не принимали совсем - $28(20,44 \%)$.

На момент включения в исследование статины принимали 84 пациента, из них постоянно получали гиполипидемическую терапию лишь 17 (21,25\%).

При детальной оценке психологического статуса по результатам опросника уровня стресса выраженный стресс выявлен у 70 (45,75\%), средний уровень стресса - у 67 (43,79\%), низкий у $16(10,46 \%)$ обследованных. Согласно шкале HADS, на I визите клинически выраженная тревога выявлена у 75 (49,03\%), субклинический уровень тревоги - у 48 (31,37\%), отсутствовали признаки тревоги - у 30 (19,60\%) пациентов. Клинически выраженная депрессия установлена у $62(40,52 \%)$ пациентов, субклини ческий уровень депрессии определен у 54 (35,29\%), низкий уровень депрессии выявлен у 37 (24,19\%). По итогам оценки психологического статуса в группу лечения препаратом Медопрам вошли $86(56,21 \%)$ больных.

На фоне лечения препаратом Медопрам (10-20 мг/сут) на протяжении 6 мес зарегистрирован положительный эффект по субъективным оценкам самочувствия пациентов и положительная динамика по оценке уровня стресса, тревоги и депрессии. Так, медиана уровня стресса до лечения составила $2(1,57-2,42)$, а в конце 6 мес приема Медопрама - 2,86 $(2,57-3,14)$ балла. Положительная динамика в группе по уровню стресса была высокодостоверной ( $<<0,00001)$. При этом высокий уровеньстресса, отмеченный до лечения у $45,75 \%$ пациентов, во время лечения отмечен лишь у $6,54 \%$ (рис. 1а, б). Такое снижение высокого уровня стресса отмечено за счет увеличения количества пациентов со средним $(50,33 \%)$ и особенно низким $(43,13 \%)$ уровнем стресса.

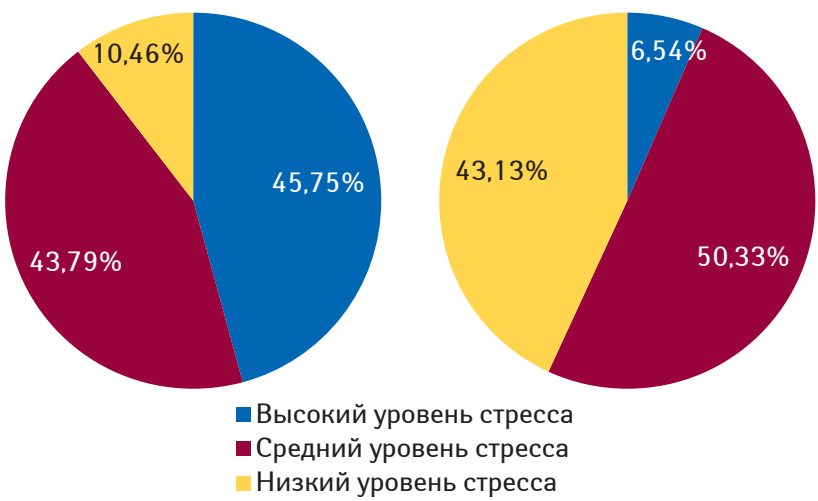

Рис. 1. Динамика уровня стресса в группе наблюдения на фоне применения препарата Медопрам

Детальная оценка динамики психологического статуса по шкале HADS показала уменьшение количества больных с клинически выраженным уровнем тревоги с 49,03 до 3,92\%, с субклиническим уровнем тревоги - с 31,37 до 24,18\% и увеличение количества больных с отсутствием достоверно выраженных признаков тревоги с 19,60 до 71,90\% (рис. 2).

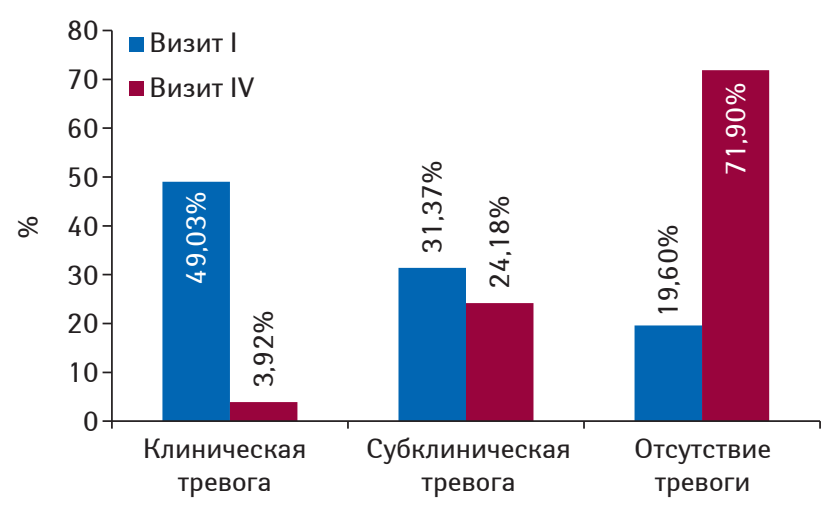

Рис. 2. Динамика уровня тревоги в группе наблюдения на фоне применения препарата Медопрам

Через 6 мес применения препарата Медопрам (рис. 3) количество пациентов с клинически выраженной депрессией снизилось с 40,52 до 1,96\%, с субклинической формой депрессии с 35,29 до 19,61\% за счет закономерного увеличения количества пациентов с отсутствием достоверно выраженных симптомов депрессии - с 24,19 до 78,43\%.

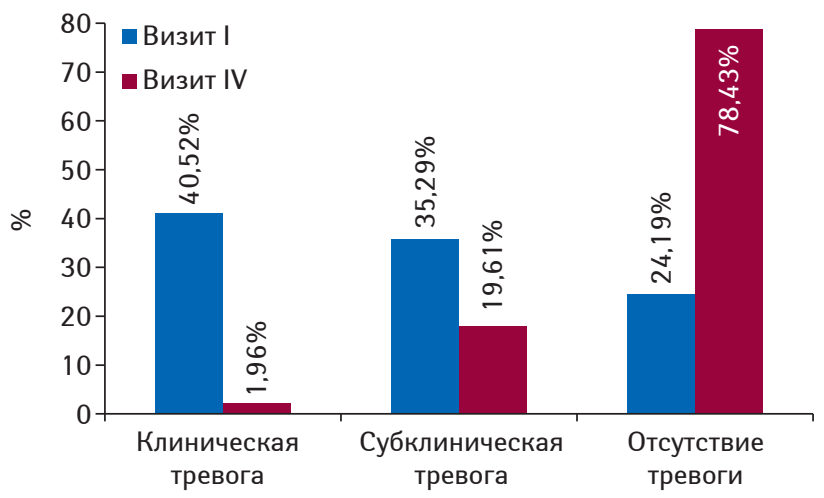

Рис. 3. Динамика депрессии в группе наблюдения на фоне применения препарата Медопрам

Одним из важных нежелательных побочных эффектов большинства антидепрессантов является удлинение интервала $Q-T$ по данным ЭКГ. Согласно результатам исследования интервал $Q-T$ у пациентов исходно составлял 0,36 (0,32-0,39) мс (таблица).

Таблица. Динамика изменения интервала $Q-T$ на фоне 6 мес применения препарата Медопрам

\begin{tabular}{lccccc}
\hline \multirow{2}{*}{ Показатель } & \multicolumn{5}{c}{ Визит } \\
\cline { 2 - 5 } & I & II & III & IV \\
\hline Интервал Q-T, мс & 0,36 & 0,38 & 0,38 & 0,38 \\
Me $(25-75)$ & $(0,32-0,39)$ & $(0,36-0,40)$ & $(0,36-0,40)^{\#}$ & $(0,36-0,40)^{*}$ \\
\hline
\end{tabular}

"Достоверность различий между I и III визитами; *достоверность различий между I и IV визитами, достоверность различий определена по критерию Манна - Уитни $(p<0,02)$.

На фоне применения препарата Медопрам через 4 нед (II визит) отмечена недостоверная тенденция к удлинению $Q-T$, на III и IV визите медиана $Q-T$ не возросла, но была достоверно выше, чем на I визите. Невзирая на выявленные колебания $Q-T$ следует отметить, что на фоне применения Медопрама на протяжении 6 мес величина интервала Q-T не превышала допустимой границы нормы - 0,43 (для мужчин) и 0,45 (для женщин), что подтверждает безопасность длительного приема Медопрама у больных с кардиоваскулярной патологией

Корреляционный анализ позволил установить, что интервал Q-T на II, III и IV визитах был тем длиннее, чем старше по возрасту был пациент ( $r=0,33 ; r=0,29 ; r=0,38 ; p<0,05$ соответственно). Важно отметить и тот факт, что длина интервала Q-T на IV визите была также ассоциирована с гиподинамией (количеством часов, проведенных сидя на протяжении дня) на І визите ( $r=0,36 ; p<0,05)$.

При проведении корреляционного анализа установлена положительная ассоциация между степенью выраженности тревоги и гиподинамией, а именно количеством часов в день, проводимых сидя $(r=0,29 ; p<0,05)$. 
Степень выраженности тревоги была тем выше у больных, чем выше был уровень стресса по опроснику L. Reeder ( $r=-0,29$; $p<0,05)$. Данная зависимость сохранялась и на IV визите ( $r=-0,30$; $p<0,05)$, что свидетельствует о сохранении взаимосвязи между повышенной тревожностью и уровнем стресса у пациентов даже на фоне приема антидепрессантов.

В ходе исследования не выявлено негативного влияния Медопрама на частоту сердечных сокращений и уровень АД. Побочные эффекты препарата (преимущественно тошнота) были выражены незначительно и имели тенденцию к быстрой спонтанной редукции без коррекции дозы или отмены препарата.

\section{Выводы}

Результаты проведенного исследования подтверждают значительную распространенность тревожно-депрессивных расстройств у больных ССЗ, что свидетельствует о необходимости включения стандартизированных диагностических методов (в том числе опросников и шкал, использованных в данном исследовании) в комплексное клинико-инструментальное обследование больных ССЗ для своевременного выявления клинически значимых тревоги и депрессии.

Высокая эффективность, безопасность, хорошая переносимость и низкий потенциал межмедикаментозного взаимодействия подтверждают особенное значение эсциталопрама (Медопрам) в лечении при тревожно-депрессивных расстройствах у больных различного возраста с ССЗ и дают основания рассматривать его в качестве средства выбора терапии данной категории пациентов в клинической практике.

\section{Список использованной литературы}

Бурчинский С.Г. (2018) Фармакотерапия постинсультной депрессии, проблема и критерии выбора антидепрессанта (https://neuronews.com.ua).

Васюк Ю.А., Довженко Т.В., Семиглазова М.В., Краснов В.Н. (2012) Тревожно-депрессивные расстройства и сердечно-сосудистые заболевания: клинические взаимосвязи и современные подходы к терапии. Сердце: журнал для практикующих врачей, Т. 11, 3(65): 155-164.

Горина Л.В. (2011) Состояние тревоги и депрессии у больных с хронической сердечной недостаточностью. Автореф. ... канд. дис. Оренбург, 108 с

Долженко М.Н. (2013) Депрессивные и тревожные расстройства в кардиологии: возможности комбинированной терапии антидепрессантом и антигипоксантом (http://www.mif-ua.com/archive/article/36740).

Марута Н.А., Мороз В.В. (2002) Невротические депрессии (клиника, патогенез, диагностика и лечение). Арис, Харьков, 144 с.

Михайлов Б.В. (2003) Проблема депрессий в общесоматической практике. Междунар. мед. журн., 9(3): 22-27.

Мосолов С.Н., Калинин В.В. (1998) Некоторые закономерности формирования, коморбидность и фармакотерапия тревожно-фобических расстройств. Тревога и депрессии. Москва, с. 217-228.

Пинчук И.Я. (2010) Распространенность психических расстройств в Украине. Журн. АМН Украины, 16(1): 168-176.

Самушия М.А., Вечеринина К.О. (2005) Патохарактерологические нарушения в отдаленном послеоперационном периоде аортокоронарного шунтирования (клиника и терапия). Психиатр. психофармакотер., 7(4): 14-18

Хаустова 0.0. (2018) На чому ґрунтується свідомий вибір психотропного препарату лікарем-інтерністом (на прикладі есцитолапраму). Ліки України, 3(219): 6 .

Чазов Е.И. (2003) Депрессия как фактор развития и прогрессирования сердечно-сосудистых заболеваний. Серд. недост., 2(1): 6-8.

Barefoot J.C., Helms M.J., Mark D.B. et al. (1996) Depression and long-term mortality risk in patients with coronary artery disease. Am. J. Cardiol., 78(6): 613-617.

Januzzi J.L.Jr., Stern T.A., Pasternak R.C., DeSanctis R.W. (2000) The influence of anxiety and depression on outcomes of patients with coronary artery disease. Arch. Intern. Med., 160(13): 1913-1921.

Kaplan H.I., Sadock B.J. (1998) Pocket handbook of clinical psychiatry Пер. с англ. Т.Б. Дмитриева (ред.). ГЭОТАР-Медиа, Москва, 512 с.
Lesperance F., Frasure-Smith N., Talajic M. (1996) Major depression before and after myocardial infarction: its nature and consequences. Psychosom. Med., 58(2): 99-110.

Musselman D.L., Evans D.L., Nemeroff C.B. (1998) The relationship of depression to cardiovascular disease: epidemiology, biology, and treatment. Arch. Gen. Psychiatry, 55(7): 580-592.

Pająk A., Jankowski P., Kotseva K. et al.; EUROASPIRE Study Group (2013) Depression, anxiety, and risk factor control in patients after hospitalization for coronary heart disease: the EUROASPIRE III Study. Eur. J. Prev. Cardiol., 20(2): $331-340$.

Tsartsalis D., Dragioti E., Kontoangelos K. et al. (2016) The impact of depression and cardiophobia on quality of life in patients with essential hypertension. Psychiatriki, 27(3): 192-203.

World Health Organization (2017) Mental health: Depression (http://www. who.int/mental_health/management/depression/en/).

Zigmond A.S., Snaith R.P. (1983) The hospital anxiety and depression scale. Acta. Psychiatr. Scand., 67(6): 361-370.

\section{Тривожно-депресивні розлади у пацієнтів із серцево-судинними захворюваннями у клінічній практиці: можливості терапії}

\section{Т.В. Колесник, А.В. Надюк, Г.А. Косова, М.Г. Киричко, В.В. Білецький}

Резюме. У статті вивчена частота клінічно виражених форм і субклінічних проявів тривоги і депресії у 153 пацієнтів із серцево-судинними захворюваннями, оцінена ефективність терапії тривоги і депресіі у цих хворих препаратом Медопрам протягом 6 міс. Підтверджено значну поширеність тривожно-депресивних розладів у пацієнтів із кардіоваскулярною патологією, що свідчить про необхідність включення стандартизованих діагностичних методів укомплексне клінікоінструментальне обстеження хворих для своєчасного виявлення клінічно значущих тривоги та депресії. Висока ефективність, безпека, хороша переносимість і низький потенціал межмедикаментозної взаємодії підтверджують особливе значення есциталопраму(Медопрам) у лікуванні тривожно-депресивних розладів у хворих різного віку з серцево-судинними захворюваннями і дають підстави розглядати його як засіб вибору в терапії цих пацієнтів у клінічній практиці.

Ключові слова: тривога, депресія, серцево-судинні захворювання, есциталопрам, Медопрам

\section{Anxiety-depressive disorders in patients with cardiovascular diseases in clinical practice: therapeutic options \\ T.V. Kolesnyk, A. V. Nadiuk, A.A. Kosova, M.G. Kyrychko, V.V. Beletsky}

Summary. The article examines the frequency of clinically expressed forms and subclinical manifestations of anxiety and depression in 153 patients with cardiovascular diseases. The effectiveness of therapy of anxiety and depression in these patients with Medopram for 6 months has been evaluated. A significant prevalence of anxiety-depressive disorders in patients with cardiovascular pathology has been confirmed, which indicates the necessity of incorporating standardized diagnostic methods into a comprehensive clinical and instrumental examination in patients for the timely detection of clinically significant anxiety and depression. High efficiency, safety, good tolerability and low potential of intermedicative interaction confirms the special importance of escitalopram (Medopram) in treatment of anxiety-depressive disorders in patients of all ages with cardiovascular diseases and gives grounds to consider it as a drug of choice in patients of this category in clinical practice.

Key words: anxiety, depression, cardiovascular diseases, escitalopram, Medopram

Получено 05.09.2018

\section{Информация для профессиональной деятельности специалистов здравоохранения}

Медопрам

P.с. UA/14937/01/01, UA/14937/01/02, UA/14937/01/03 от 16.03.2016 г.

Состав: 1 таблетка, покрытая пленочной оболочкой, содержит 5; 10 или 20 мг эсциталопрама. Фармакотерапевтическая группа. Антидепрессанты. Селективные ингибиторы обратного захвата серотонина. Код АТC. N06АВ10. Фармакологические свойства. Эсциталопрам является антидепрессантом, селективным ингибитором обратного захвата серотонина, что обусловливает клинические и фармакологические эффекты препарата. Обладает высоким сродством к основному связующему элементу и смежному с ним аллостерическому элементу транспортера серотонина и не обладает совсем или обладает очень слабой способностью связываться с рядом рецепторов, включая серотониновые 5-HТ - 5-НТ -рецепторы, дофаминовые $D_{1}$ - и $D_{2}$-рецепторы, $a_{1}$-, $a_{2}$-, $\beta$-адренергические рецепторы, $H_{1}$-, мускариновые холинергические, бензодиазепиновые и опиатные рецепторы. Показания: лечение при больших депрессивных эпизодах, панических расстройствах, в том числе агорафобии, социальных тревожных расстройствах (социальная фобия), генерализованных тревожных расстройствах, обсессивнокомпульсивных расстройствах. Побочные эффекты: тромбоцитопения, анафилактические реакции, нарушения секреции антидиуретического гормона, снижение или усиление аппетита и др. Полная информация о лекарственном препарате содержится в инструкции по медицинскому применению. 